\title{
CONSIDERACIONES SOBRE EL COMERCIO Y EL PAPEL DE LA PLATA HISPANOAMERICANA EN LA TEMPRANA GLOBALIZACIÓN, SIGLOS XVI-XIX
}

\author{
Mariano Bonialian \\ El Colegio de México \\ Bernd Hausberger \\ El Colegio de México
}

INTRODUCCIÓN

\begin{abstract}
$\mathrm{F}^{\text {ntendemos por globalización, de forma pragmática, el }}$ Croceso de construcción de un amplio entramado de relaciones de diversa índole, las que en su conjunto cubren el globo e impactan el desarrollo de sus partes. ${ }^{1}$ Los mecanismos de conexión han sido varios, como las ciencias, la expansión imperial, la misión, la movilidad humana y el flujo de información y de bienes. Los vínculos largos, globales o globalizadores se establecen, por lo general, en un contexto de competencia y conflicto. Muchas conexiones tienen un alto grado de institucionalización, reglas establecidas para promover intereses particulares y excluir posibles competidores. Al mismo tiempo, la
\end{abstract}

Fecha de recepción: 28 de febrero de 2017

Fecha de aceptación: 27 de septiembre de 2017

${ }^{1}$ Para más detalle, Hausberger, “Acercamientos”. 
imposibilidad de un control eficaz ha dejado grandes márgenes, tanto a las relaciones ilegales e informales como a la agencia de los actores históricos.

Si aceptamos esta amplia definición, hay razones para abogar en favor de un temprano inicio de la globalización en el siglo XVI. Tal cronología merecería más discusión, pues hay opiniones opuestas al respecto, pero coincide con los trabajos de grandes eruditos, desde Adam Smith hasta Fernand Braudel, quienes vieron en el siglo Xvi un cambio decisivo en la historia mundial. Tenemos, entre 1500 y 1600, una época de transición. Para 1500, las macrorregiones de Eurasia (Europa, el mundo islámico, la India, China) y el Norte y Este de África, habían desarrollado características distintivas y estaban conectadas de múltiples formas. En contraste, América presentaba una integración regional más débil y no existían contactos firmes entre las civilizaciones andinas y las mesoamericanas. Después de 1500, las relaciones interregionales se intensificaron sensiblemente, incluyendo por primera vez el hemisferio occidental, debido a los navegantes y conquistadores europeos. Según Jean-Michel Sallmann, hacia 1600 finalizó el proceso del desenclavement de las grandes civilizaciones, iniciado alrededor de $1200 .^{2}$ Según Dennis O. Flynn y Arturo Giráldez, con este proceso empezó la globalización. Los dos autores destacan que la palabra "globalización” deriva de "globo", un concepto espacial. Colocan, por consiguiente, la vinculación de espacios en el centro de su argumentación. Discurren que para 1500 dos terceras partes de las masas globales ya estaban conectadas de forma duradera. Durante el siglo xvI, se enlazó a ellas el tercer tercio, es decir, América o el Nuevo Mundo, mediante la apertura de la navegación transatlántica por Colón en 1492, de la ruta del Cabo entre Europa y Asia por Vasco da Gama en 1497-1498, la primera circunnavegación del globo por Fernando de Magallanes y Juan Sebastián Elcano en

${ }^{2}$ Sallmann, Le grand désenclavement. 
1519-1521, y el inicio del tráfico transpacífico entre Acapulco y Manila, en 1571. Como resultado, las rutas de comunicación por primera vez abarcan todo el globo (con excepción de Australia). ${ }^{3}$ En el marco de esta premisa, de que la globalización es un proceso que abarca (tendencialmente) todo el globo, con fuerte protagonismo americano, nos parece inadecuado el análisis de Jan de Vries, quien afirma que "the real test of early globalization [...] requires a study of Eurasia", dejando de lado los vínculos trasatlánticos y transpacíficos. ${ }^{4}$

Durante los siglos XVII y XVIII, la comunicación y el tráfico se realizarán a lo largo de las antiguas redes de intercambio eurasiáticas y de las rutas abiertas en el siglo xvi. Los esfuerzos por encontrar un paso del noroeste o del noreste por el océano Ártico de Europa a Asía oriental fracasaron, y la vía por el Cabo de Hornos tardaría en usarse con regularidad hasta bien entrado el siglo xviII, no obstante varios intentos de su apertura. ${ }^{5}$ Mientras que el sistema de rutas marítimas no cambió, sus centros de gravedad se desplazaron, sobre todo en Europa, donde durante el siglo Xvir los Países Bajos, Inglaterra y Francia les arrebataron el liderazgo a las monarquías ibéricas. Desde el principio, los contactos establecidos dejaron una profunda impronta en los espacios afectados. La transformación drástica que vivió América Latina será un hecho inédito en su historia.

Las conexiones globales fueron impulsadas en gran medida por actores de origen europeo. Pero el sistema mundial de la época dependió de la dinámica de sus partes, en las cuales, con excepción de América, los europeos sólo tuvieron una influencia limitada y más bien aprovecharon las posibilidades que se les ofrecían. Sin la intensiva cooperación e interacción con actores noeuropeos, esto hubiera sido imposible. De esta forma, surgió

\footnotetext{
${ }^{3}$ FlynN y GiRáldez, "Los orígenes".

${ }^{4}$ De Vries, "The limits of globalization", pp. 715-716.

5 Bonialian, "Geopolítica”.
} 
un orden global multipolar, cuyas bases económicas se constituyeron por la producción manufacturera de Eurasia y los metales preciosos de América. En el siglo XviI, se añadieron los productos de las plantaciones de los europeos en ultramar, con lo que los esclavos africanos se convirtieron en una de las mercancías más importantes del comercio transcontinental. ${ }^{6}$ Realizaron una parte sustancial del trabajo en los sectores claves de esta temprana economía global, en las plantaciones, en los placeres de oro y - en menor medida - en la minería de plata. ${ }^{7}$

Hacia finales del siglo xviII, la globalización entró en una nueva fase caracterizada por la hegemonía occidental, ante todo británica. China y el espacio asiático comenzaron a retroceder en la gravitación global, para dar paso al control absoluto de los europeos en los circuitos globales de comercio. A partir de entonces, las manufacturas en Medio Oriente, la India y China, y asimismo los obrajes latinoamericanos se verían profundamente afectados por la competencia de las jóvenes industrias europeas. La antigua superioridad manufacturera de Asia menguaba, y con ella la diversidad de sus exportaciones. ${ }^{8} \mathrm{El}$ proceso de europeización de la globalización fue un fenómeno de extrema trascendencia, y su evolución la han intentado analizar, entre otros, Christopher Bayly y Jürgen Osterhammel. ${ }^{9}$ Han insistido en el cambio radical que se dio en el siglo xix, pero ambos (y otros autores más) no han prestado la debida atención, por un lado, a la historicidad de este cambio (a su path dependence, según Flynn y Giráldez) ${ }^{10}$ ni tampoco al protagonismo de América Latina. De tal manera, aquí se busca resaltar que la hegemonía británico-europea decimonónica sólo pudo surgir

\footnotetext{
${ }^{6}$ Zeuske, Sklavenhändler, p. 125.

7 INIKORI, Africans, pp. 196-198.

${ }^{8}$ VRIEs, State, pp. 168-175.

9 Bayly, El nacimiento; Osterhammel, La transformación.

${ }^{10}$ Flynn y Giráldez, "Path Dependence".
} 
en el marco de un mundo ya globalizado y que América Latina jugó en él una función clave.

\section{EL MUNDO ECONÓMICO ANTES DE LA CONQUISTA Y COLONIZACIÓN DE AMÉRICA}

De forma esquemática, se puede constatar que, antes de que América fuera conquistada y colonizada, en el sistema eurasiático fluían, sobre todo, metales preciosos de oeste a este y mercancías elaboradas y de lujo de este a oeste. Ahí radicaba la función de los europeos, que disponían de ricas minas de plata. Su producción, así como la de otras partes (el oro de Sumatra o de la África subsahariana, la plata otomana y, sobre todo, japonesa), constituía la moneda de cambio dominante en los mercados de Europa y Asia. ${ }^{11}$ En el Mediterráneo, fueron los italianos, ante todo los venecianos, los que controlaron la distribución de los productos asiáticos que adquirían en el Levante y en Egipto. Con su reventa, hacían pingües ganancias, con las que podían refinanciar y aumentar sus importaciones. De esta forma no cesaron de introducir metales preciosos a los circuitos eurásicos.

La iniciativa que rompería el sistema comercial medieval partió, a principios del siglo xv, de un actor marginal, del pequeño reino de Portugal. En 1415, los portugueses conquistaron Ceuta en el noroeste de África para ganar el acceso al oro del Sáhel. Al frustrarse esta esperanza, empezaron a avanzar en la costa africana hacia el sur y a ocupar las islas situadas en su cercanía. Adquirían productos como pimienta africana o marfil, de valor muy inferior al comercio levantino de los italianos. ${ }^{12}$ Copiando un negocio que los venecianos practicaban en el oriente mediterráneo, introdujeron el cultivo de la caña de azúcar en sus islas atlánticas. El trabajo lo realizaron esclavos que compraban en la

11 Hausberger e Ibarra, “Introducción”, pp. 11-12.

12 Northrup, “Early European Contacts”, p. 45. 
costa africana, con lo que los portugueses iniciaron el comercio negrero en el Atlántico. Pronto el azúcar de Madeira competiría con la producción veneciana. Cuando en los años ochenta del siglo xv los lusitanos llegaron a la llamada Costa de Oro, en lo que hoy es Ghana, lograron acceder al oro africano. ${ }^{13}$ En 1488, doblaron el cabo de Buena Esperanza, el extremo sur de África, y en 1498 la expedición de Vasco da Gama llegó a Calicut (Kozhikode) en la India. El éxito de concretar la nueva ruta intercontinental permitió a los portugueses edificar una navegación regular al océano Índico traficando especias y otros productos de lujo para la demanda europea. Financiaron su comercio oriental con el oro africano y con la plata, el cobre y el latón adquiridos con la venta de azúcar y especias, sobre todo en su factoría en Amberes. ${ }^{14}$ En 1500, la segunda expedición portuguesa a la India, en su ruta por el Atlántico abierto, llegó al litoral de Brasil. En 1509 conquistaron Goa en la India, y en 1511 Malaca, en el estrecho entre Sumatra y la península malaya. En 1513, se establecieron en las Molucas, las legendarias islas de las especias. En 1515 llegaron a China y en 1543 a Japón. Como dijera Bayly, el Imperio portugués en Asia fue, de esta suerte, una enorme ampliación de la "talasocracia” mediterránea, es decir, de un sistema de bases costeras sin mayor binterland conectadas por rutas navieras, como las habían construido los fenicios, los antiguos griegos o los venecianos. ${ }^{15}$

Como veremos, la incorporación de América a los intereses españoles y a los circuitos globales tomaría formas distintas. Por el momento baste recordar que, en 1492 Cristóbal Colón partió en busca de una ruta alternativa a la India y China, pero llegó a las Antillas. De esta forma, los ibéricos abrieron tanto el Atlántico como el Índico a la navegación europea. Las expediciones

13 Northrup, “Early European Contacts”, pp. 43-44.

14 Feldbauer, Estado da India, pp. 153-160.

15 BAYLY, “Archaic' and 'Modern' Globalization”, pp. 61-62. 
por el Pacífico no se harían esperar. En 1513, Vasco Núñez de Balboa atravesó el istmo de Panamá y, en 1520, Magallanes entró al Pacífico por el estrecho que desde entonces lleva su nombre. De esta suerte, el Pacífico se colocó en la órbita de los intereses españoles. Después de una serie de expediciones marinas, se apoderaron de las islas Filipinas y fundaron Manila en 1571. Por las mismas fechas se inauguró la comunicación regular entre Manila y el puerto novohispano de Acapulco, con el legendario galeón de Manila. El puerto filipino se convirtió en el entrepôt del intercambio entre América y China. El gobierno de los Ming favoreció este desarrollo más bien por casualidad, cuando casi simultáneamente abrió el pequeño puerto de Yuegang para el comercio exterior. ${ }^{16}$

LOS EJES GEOHISTÓRICOS Y MERCANTILES

DE HISPANOAMÉRICA EN LA GLOBALIZACIÓN

De esta suerte, América ingresó al juego global de intercambios de las economías del mundo preexistentes. Lo hizo, fundamentalmente, a partir de la creación de ejes geohistóricos que unieron el continente con Asia, por el Pacífico, y con España/Europa, por el Atlántico. Hasta hace pocos años, los estudios sobre la participación mercantil de América en el escenario mundial de comercio se limitaron a su orientación trasatlántica, en una unilateral visión de los contactos ya sea con España mediante el comercio legal, o con Europa, plasmado en el contrabando o los permisos autorizados. Estudios recientes han demostrado el notable peso que constituyó el nexo entre la América hispana y las islas Filipinas y China por el lado del Pacífico. ${ }^{17}$ Aquí, intentamos alcanzar una imagen completa e integradora de los

\footnotetext{
${ }_{16}$ ZhaO, The Qing Opening, pp. 25-26.

17 Bernal, "La carrera"; Bernabéu Albert y Martínez Shaw, Un océano; Yuste, Emporios; Bonialian, El Pacífico.
} 
circuitos americanos en la globalización, evitando caer en una visión eurocéntrica de los mismos.

Los ejes geohistóricos construidos desde y hacia América ilustran los modos de su integración a la globalización. ${ }^{18} \mathrm{El}$ término, familiarizado por la historia de larga duración, fue acuñado por Fernand Braudel y luego continuado por algunos de sus discípulos, como Pierre Chaunu. ${ }^{19}$ Pero, ¿cómo definimos al eje geohistórico? Se refiere a la existencia de unas estructuras suprarregionales, poco cambiantes, por donde vemos actuar las prácticas sociales, económicas y políticas de los agentes históricos. Los ejes geohistóricos se descubren sólo si logramos combinar el enfoque microhistórico con el nivel transregional y global. Al descubrir los modos y las características relacionales que cada bloque indiano diagramó en su contacto con el exterior, lograremos identificar las plataformas o los escenarios donde actuaron los intereses de los agentes históricos. Los ejes macroespaciales y de larga duración no sólo dinamizaron los espacios regionales (micro), sino también las conexiones de la economía local interna con unidades macroeconómicas. De tal manera, los grandes ejes no tienen la capacidad para ejercer un control real y efectivo sobre los territorios, pero otorgan sentido a la red de relaciones de larga distancia que los conecta.

Desde un abordaje atlántico europeo, podemos distinguir dos grandes ejes que configuran el espacio americano para su contacto con el exterior. Uno de ellos es el que conectaba a Europa/España con el puerto de Veracruz en el virreinato novohispano. De Veracruz el eje proseguía por vía terrestre hasta su centro, la ciudad de México, alcanzando la otra orilla del espacio virreinal: el puerto de Acapulco. Fue un eje novohispano horizontal que unió a dos mundos marítimos muy diferentes en su

18 Carmagnani, "La organización"; Chaunu, "Veracruz"; Bonialian, China en la América, pp. 27-82.

19 Braudel, "Historia”; Chaunu, Historia. 
naturaleza y características, el Atlántico y el Pacífico. La ciudad de México, mediante el poder de sus comerciantes, se convirtió en el epicentro del eje, articulando las economías mercantiles de ambas áreas de navegación marítima. Ciertamente, el eje novohispano se conectó con el mundo atlántico español, sujeto a las grandes escuadras comerciales que descansaban previamente en La Habana, antes de llegar a la costa veracruzana: las flotas de Veracruz. Los cargamentos enviados desde Sevilla (y más tarde, Cádiz) hacia el Sotavento fueron controlados por los mercaderes peninsulares, quienes monopolizaron las exportaciones de los productos europeos y españoles para el consumo novohispano. Los grandes comerciantes de la ciudad de México, protegidos y amparados en el Consulado, monopolizaron la distribución de los bienes europeos por el mercado interno virreinal, y la exportación de plata como forma de pago. Además de conectarse con las rutas del contrabando con las diversas potencias europeas en el Caribe y hasta Norteamérica, el eje novohispano se enlazó al mundo del Pacífico gracias a las navegaciones realizadas por el galeón de Manila. La movilización comercial por ambos puertos (Veracruz y Acapulco) fue operada por los comerciantes de la ciudad de México, colocando a dichos agentes y a dicho espacio en una posición geopolítica privilegiada en el comercio global, en el centro económico hispanoamericano para los contactos directos con Asia y Europa. El eje novohispano, además, gravitó profundamente en el espacio sudamericano, en particular con Perú, a partir de los contactos (desde 1630 ilegales) entre Acapulco y el puerto peruano del Callao. ${ }^{20}$

El segundo gran eje geohistórico trasatlántico se construyó entre España y Portobelo (Panamá), con su extensión por el Pacífico hacia la ciudad de Lima. El eje sudamericano partía desde España, viviendo su primera articulación económica en Portobelo, con ferias celebradas en Panamá. Desde allí y por vías

${ }^{20}$ Bonialian, El Pacíico, pp. 42-74. 
marítimas y escalas circunstanciales en Guayaquil, el eje transitaba por el Pacífico sur hasta concluir en el puerto de El Callao, punto importador y exportador del centro económico y político del virreinato de Perú: la ciudad de Lima. Dos importantes espacios, como lo fueron Santiago de Chile y Buenos Aires, necesitaron derroteros, vías de prolongación, para poder unirse al funcionamiento del eje Portobelo-Lima. El primero de ellos se configuró por vías marítimas, conectando al puerto del Callao con Valparaíso, punto costero más cercano al centro de Santiago. La extensión del eje sudamericano fue el que se edificó entre Lima-Potosí-Buenos Aires. La ciudad puerto del Río de La Plata, además de constituir un punto de entrada de esclavos hacia el interior de Sudamérica, fue el canal de ingreso de bienes europeos, y de salida de plata potosina mediante el llamado contrabando portugués, que operaba por el Atlántico sudamericano y desde Brasil. Es decir, fue un flujo - al igual que el construido entre México y Perú por el Pacífico - que amenazó el statu quo mercantil del imperio sustentado en el esquema monopólico español de las flotas y ferias de Portobelo y Veracruz. ${ }^{21}$

Para tener un cuadro completo de la inserción hispanoamericana a la globalización mercantil, debemos incorporar la perspectiva pacífica. Desde muy temprano, a partir del momento en que se inaugura la ruta de tornaviaje del galeón de Manila (1571), apareció un eje geohistórico entre las islas Filipinas, Acapulco, ciudad de México y El Callao. Fue una gran plataforma espacial donde la movilidad de bienes y plata adquirió, desde principios del siglo XVII, un carácter informal, puesto que el único circuito por el Pacífico reconocido legalmente por la corona española fue el del galeón de Manila, rígidamente regulado desde 1593. El eje por el Pacífico tuvo una vida extensa, iniciándose con la nao de China y minimizándose hacia mediados del siglo xviII, cuando se oficializa el circuito español que buscaba los mercados

${ }^{21}$ Bonialian, "México, epicentro". 
del Pacífico sudamericano por el Cabo de Hornos. Durante ese largo periodo colonial, el eje del Pacífico hispanoamericano tuvo la capacidad de influir sobre los ejes trasatlánticos mencionados. ${ }^{22}$ En segundo lugar, a diferencia de los ejes asentados y trazados por Veracruz y Portobelo, el del Pacífico funcionó desde la ilegalidad, donde si bien su dinámica económica fue promovida por agentes económicos consulares de la ciudad de México y de Lima, resultó combatida por el poder peninsular de la Monarquía, al notar los efectos que causaba sobre el comercio trasatlántico.

Continuando con un análisis desde el Pacífico americano, es necesario reconocer un circuito que surgió en precisas coyunturas coloniales: el edificado entre El Callao, las islas Filipinas y Cantón (China). En este caso nos encontramos con un área de circulación naval circunstancial y esporádica que se desarrolló entre 1580-1600 y $1695-1718 .{ }^{23}$ En ambas etapas, el flujo transoceánico se vio impulsado por diferentes factores: el auge en la producción de plata, la estimación de la plata en el mercado asiático y el consumo ascendente de bienes orientales en el mercado andino. ¿Por qué fue un eje circunstancial y no regular? La respuesta aparece al notar el papel clave que tuvieron Nueva España y su puerto de Acapulco como paso intermedio para que el Perú participara de los beneficios del comercio con Asia.

Llegamos así al último eje que apareció en el tardo periodo colonial y que reforzó la integración del espacio hispanoamericano a la economía global. Nos referimos al circuito que enlazó a España con los mercados sudamericanos con los navíos de registro. Nació formalmente en 1739 con la desintegración del eje trasatlántico España-Portobelo-Lima. A partir de ahí, la corona española institucionalizó el navío de registro como medio de transporte dominante para los puertos del Atlántico

22 Bonialian, China en la América, pp. 27-82.

${ }^{23}$ Iwasaki Cauti, Extremo Oriente. 
sudamericano (Buenos Aires) y, transitando por el Cabo de Hornos, con los puertos del Pacífico (Valparaíso, Callao, Guayaquil, por nombrar los más importantes). Fue un contexto diferente al anterior, pues dicho circuito se inscribió en el periodo de reformas borbónicas, cuando la Monarquía Hispánica se encontraba implementando el sistema de "libre comercio". Los navíos de registro españoles atravesaban el Cabo de Hornos con la intención de proveer de bienes europeos (particularmente textiles) a los mercados consumidores de la América occidental..$^{24}$ Algunos de estos navíos peninsulares alcanzaron las costas del Pacífico novohispano. El nuevo eje borbónico buscó reforzar los intereses mercantiles de la península Ibérica. Por un lado, cuestionó y combatió los privilegios que antaño tenían los consulados indianos. Por otro estableció políticas económicas que tendían a minimizar el contrabando europeo y el comercio informal novohispano entre Manila, Acapulco y Perú. La aparición del eje por el Cabo de Hornos fue un golpe mortal a la histórica inclinación del Pacífico hispanoamericano hacia la economía asiática, poniendo en crisis el comercio del galeón de Manila y orientando de ahora en más los mercados del Pacífico sudamericano a la economía europea. Estamos en presencia, a partir de 1750, de un proceso de "atlantización” o "europeización” del comercio por el Pacífico, llevando a su mínima expresión la gravitación de China sobre los mercados americanos. ${ }^{25}$ El eje por el Cabo de Hornos va de la mano de la autorización a nuevos puertos al comercio directo (como Buenos Aires y Valparaíso), que motiva la emergencia de las élites regionales.Una conclusión final sobre los ejes espaciales reseñados. A excepción del último eje del Cabo de Hornos, todos los restantes que actuaron hasta la mitad del siglo xviII deberían ser contextualizados en el gran

${ }^{24}$ LAmikiz, "Patrones de comercio".

${ }^{25}$ Una segunda ola comercial que vino a profundizar la europeización del Pacífico fue el comercio británico por el eje Jamaica - Panamá - San Blas. Dicho eje funcionó a partir de 1790; véase Bonialian, “Comercio y atlantización”. 
marco de la globalización policéntrica. Partimos de la premisa de que el comercio fue la pieza central para que grandes zonas continentales del globo lograran interactuar en la temprana modernidad. En esa interconexión, el comercio ayudó para que centros o nodos que motorizaban determinadas economías macrorregionales pudieron relacionarse. Durante las últimas décadas del siglo XviII, en los prolegómenos de la revolución industrial inglesa, los ejes mercantiles hispanoamericanos terminaron por ser cooptados por la economía europea, en particular por el comercio británico.

\section{PRODUCCIÓN Y CIRCULACIÓN DE PLATA AMERICANA EN LA GLOBALIZACIÓN}

El aporte más trascendental del bloque continental americano a la globalización fue proveer metales a sus mercados. ${ }^{26}$ Muchos de los ejes mercantiles reseñados tuvieron como principal función la exportación de plata producida en Perú y en Nueva España hacia las economías de Europa y de China. Un hecho concreto lo constata: según los clásicos cálculos de Gunder Frank, entre 1500 y 1800 América habría producido 87\% de la plata mundial. Dicho porcentaje se discriminaría por centurias de la siguiente forma: 17000 toneladas en el siglo XVI, 420000 en el XVII y 740000 en el XVIII. ${ }^{27}$ Los cálculos de Frank parecen confirmarse con los que brindó en su momento Cross. Él estimó que el porcentaje de plata peruana y novohispana que habría fluido por los mercados mundiales en el siglo XviII alcanzó un notable $89.5 \%$. Si bien para los siglos anteriores el porcentaje fue menor, no por ello fueron insignificantes: $68.5 \%$ en el XVI y $84.4 \%$ en la centuria siguiente. ${ }^{28}$ Durante el siglo Xvi y gran

${ }^{26}$ Queda al margen de nuestro estudio el oro brasileño, que también cumplió un papel destacado en la circulación metalífera por el globo.

27 Frank, ReOrient, pp. 143-150.

28 Cross, "South American Bullion”, p. 403. 
parte del XVII las minas peruanas se colocaron como el principal centro productor de plata de América y del planeta. En aquel primer siglo, Perú ofreció 57\% de plata a los mercados de Asia y Europa, mientras que México sólo 11.4\%. El cerro de Potosí se convirtió en el tesoro metalífero del globo. Esos menores porcentajes que aparecen para los siglos XVI y XVII se deben al importante papel que tuvo la plata japonesa en la economía asiática, en particular en China; una función que desaparecerá hacia la mitad del siglo Xvir, a raíz de que el gobierno nipón prohibió su exportación.

Conforme avanzaron las décadas del siglo XviI, pero fundamentalmente en el siglo de la dinastía borbónica, México, con su multitud de grandes, medianas y pequeñas minas, ${ }^{29}$ se ubicó en el primer lugar, desplazando a Perú como polo productor metalífero del mundo. En el siglo xviıi México proveyó al mundo $57 \%$ de su plata, mientras que Perú 32.5\%. Es verdad: este conjunto de cifras puede recibir una justificada crítica si se aspira a cálculos exactos. Sin embargo, siguen siendo válidas a la hora de estimar el papel trascendental que cumplió la plata americana en los circuitos y mercados de la temprana globalización.

Ahora bien, antes de analizar las exportaciones de metálico por cada uno de los ejes reseñados, valdría la pena hacernos una pregunta: ¿qué efectos, consecuencias o implicaciones tuvo en los mercados internos hispanoamericanos la disposición del metal? La pregunta nos lleva a considerar un rico debate historiográfico que se generó en décadas pasadas y que lamentablemente ha caído en el olvido. Se trata de interpretaciones historiográficas disímiles entre dos reconocidos historiadores: Ruggiero Romano y Carlos Sempat Assadourian. Según Romano, la plata americana exportada hacia Europa y Asia, ya sea por contrabando o por comercio legal, provocó que los mercados internos de América viveran una suerte de "economía natural”;

${ }^{29}$ Hausberger, La Nueva España, pp. 82-87. 


\section{Gráfica 1}

PRODUCCIÓN DE PLATA DEL VIRREINATO DE PERÚ

Y NUEVA ESPAÑA EN EL SIGLO XVIII

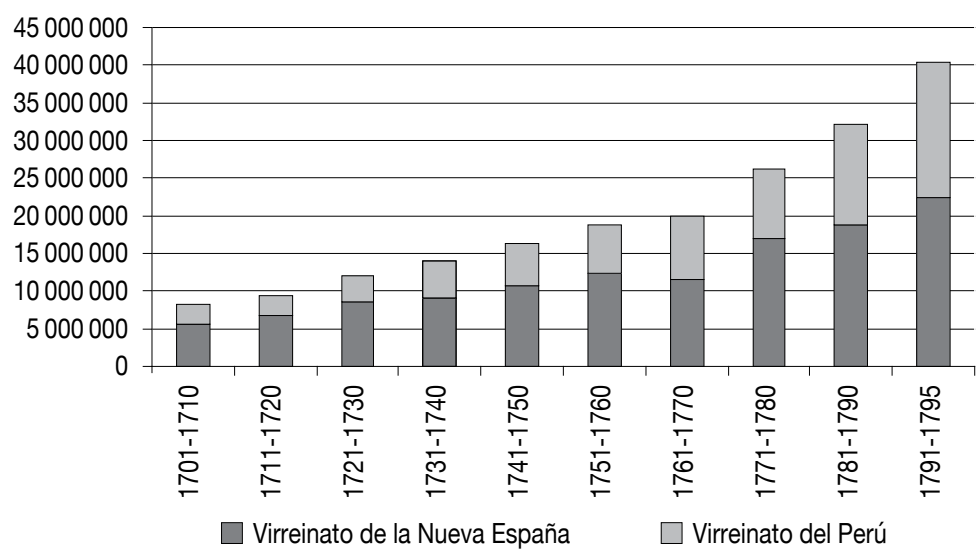

Fuente: Bonialian, El Pacífico hispanoamericano, pp. 32-33.

mercados con nula o escasa monetización. ${ }^{30} \mathrm{Al}$ analizar el caso novohispano del siglo XvIII, Romano sugiere una realidad reposada en una economía natural agraria, en el intercambio simple, en el trueque. La economía de mercado, monetizada, habría sido marginal y la circulación monetaria habría inhibido la formación de un mercado interno articulado y fuerte. Esta debilidad habría motivado la expulsión de numerario por vías de contrabando o por flujos legales de comercio hacia las potencias europeas. De tal manera, Romano considera la exportación de plata como una “expulsión” de riqueza americana, un "escape” de metálico que no benefició a las economías y el comercio interno de América.

Assadourian nos pinta un cuadro radicalmente opuesto al explorar lo que llamó el espacio peruano colonial. Nos dice que la notable producción de plata del cerro de Potosí a partir de la

${ }^{30}$ Romano, Moneda; Ibarra, "Mercado colonial”. 
segunda mitad del siglo xvi hizo que las economías regionales del espacio se mercantilizaran. Antes de ser "expulsada” hacia el exterior, la plata peruana cumplía un papel fundamental en el mercado interno al ser un medio de cambio utilizado por agentes del virreinato en los mercados locales como una "mercancía-dinero". Esta instancia previa de “realización” en dinero de la plata fue compatible y funcional con la exportación de numerario hacia China y Europa. Es decir, antes de que llegara a los puertos para exportarse, la plata americana circulaba por los mercados internos para ser intercambiada por productos locales y extranjeros, logrando generar un mercado consumidor local significativo, en particular en ciudades como Lima y Potosí. ${ }^{31}$ Siguiendo el pensamiento de Assadourian, la exportación de plata fue compatible con el crecimiento económico del espacio interno peruano. Esto significó una profunda reconfiguración del espacio y de su orden económico. Incluso al sector de subsistencia de los indios le fue asignada una función, sobre todo como reserva de mano de obra y su reproducción. ${ }^{32}$ Cuando la producción de plata peruana evidenció claros signos de descenso y estancamiento en la segunda mitad del siglo xviI, el espacio peruano perdió su capacidad de autosuficiencia y comenzó su fragmentación, configurando nuevas realidades como la ruralización, la economía natural y la desmonetización interna.

\section{LA EXPORTACIÓN DE PLATA AMERICANA}

EN LA GLOBALIZACIÓN

Ahora sí, ampliando el escenario a escala global, valdría preguntarnos sobre los efectos que tuvo la enorme masa de metal precioso en la globalización. Notables trabajos han puesto de manifiesto los efectos generados por los flujos de plata

\footnotetext{
31 Assadourian, “La producción”.

32 Véase también Tandeter, Coacción.
} 
americana en el desarrollo de la economía europea, procesos definidos como la "acumulación originaria” y la "revolución de los precios”. ${ }^{33}$ Otro debate versa sobre la crisis y el derrumbe de la dinastía Ming en China, en 1640.34 Los mercados de la globalización se vieron afectados por la importación de plata, revolucionando los sistemas monetarios europeos y asiáticos, que según los especialistas provocaron situaciones inflacionarias y de devaluación de la moneda. Aun con estos efectos adversos, diferentes áreas económicas utilizaron la plata en el sistema de salarios y jornales, y en actividades económicas estatales como la extracción fiscal. De tal manera, la moneda peruana y mexicana que se exportaba por el Atlántico (hacia Europa) o por el Pacífico (hacia China) se convirtió en el medio de pago dominante en el comercio intercontinental para saldar las importaciones de bienes internacionales que eran necesarios para el consumo hispanoamericano. Tanto los productos exóticos y lejanos como los esclavos africanos alcanzaban su cotización a partir del cálculo de pesos en plata.

Veamos los circuitos de exportación de metálico que se tejieron desde Hispanoamérica hacia Europa y China. El mapa 1 brinda mayor claridad a nuestra explicación. Desde un primer momento, habría que diferenciar los flujos oficiales y de contrabando que conectaron a América con España y a América con Europa. En cuanto a los primeros, una referencia obligada es la carrera de Indias. Las flotas veracruzanas perduraron hasta 1778. Para el caso sudamericano, el régimen se asentó sobre los galeones de Tierra Firme que dejaron de funcionar hacia 1740. Los convoyes de Tierra Firme movieron la plata peruana de Portobelo a España, luego de haber arribado a Panamá con la Armada del Sur procedente del puerto del Callao. Existió un

${ }^{33}$ Marx, El capital, t. 1, p. 639; Hamilton, American Treasure; Pieper, "Las repercusiones".

${ }^{34}$ Atwell, "Another Look", quien revisa críticamente los datos de Von Glahn, "Myth and Reality". 


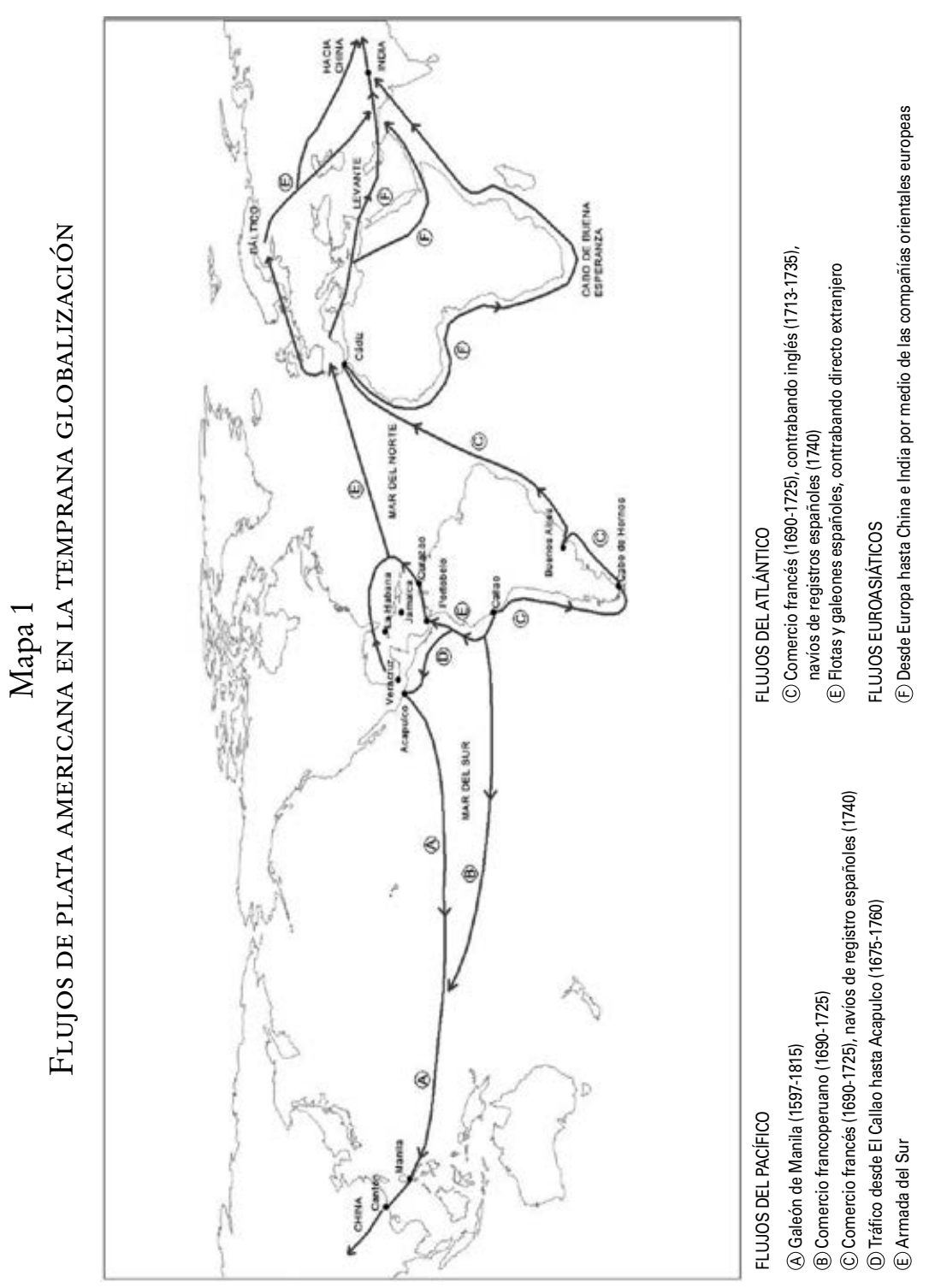


tercer tipo de transporte español que logró transferir los excedentes metálicos hacia España: los denominados navíos de registro. El régimen de los navíos particulares comenzó a funcionar de manera frecuente cuando la flota de Portobelo desapareció.

Los canales ilegales de salida de plata americana hacia Europa fueron variados y numerosos. La presencia de franceses, ingleses y holandeses cerca de los puntos oficiales de extracción de metálico (Veracruz y Portobelo) alentó sistemáticamente su flujo informal. También Buenos Aires fue punto de salida de plata peruana en forma de contrabando. Por su parte, los franceses lograrán extraer sumas muy importantes de ella en las dos primeras décadas del siglo XviII; momentos de estrecha vinculación diplomática entre las coronas borbónicas de Francia y España. También exportaron plata novohispana desde Veracruz con la incesante llegada de navíos particulares. Sin embargo, la mayor extracción de metálico por parte de los galos se registró en América del Sur, por la ruta del Cabo de Hornos y con la concesión del asiento de esclavos desde 1702 hasta 1712. Lo mismo harán años más tarde los ingleses, cuando España les conceda en 1713 el propio asiento de negros y la autorización para comerciar en las Indias con el navío de permisión de 500 toneladas. Los ingleses no sólo seguirán abasteciéndose de plata americana por el comercio directo de Jamaica, sino que mediante concesiones oficiales tendrán una presencia sistemática en varios puertos americanos, como Veracruz, Portobelo y Buenos Aires.

En el cuadro 1 consideramos las estimaciones presentadas por Attman y Morineau sobre la importación de metálico americano. El primero atendiendo a las entradas por la Península y, el segundo, para las importaciones oficiales y de contrabando por Europa. ${ }^{35} \mathrm{Si}$ tenemos en cuenta que 1 peso de a 8 reales equivalía a 25.56 gramos de plata y rescatamos las cifras ofrecidas por

${ }^{35}$ Attman, “The Bullion Flow”, p. 68; Morineau, Incroyables gazettes, cuadro 70 , pp. 474-476. 


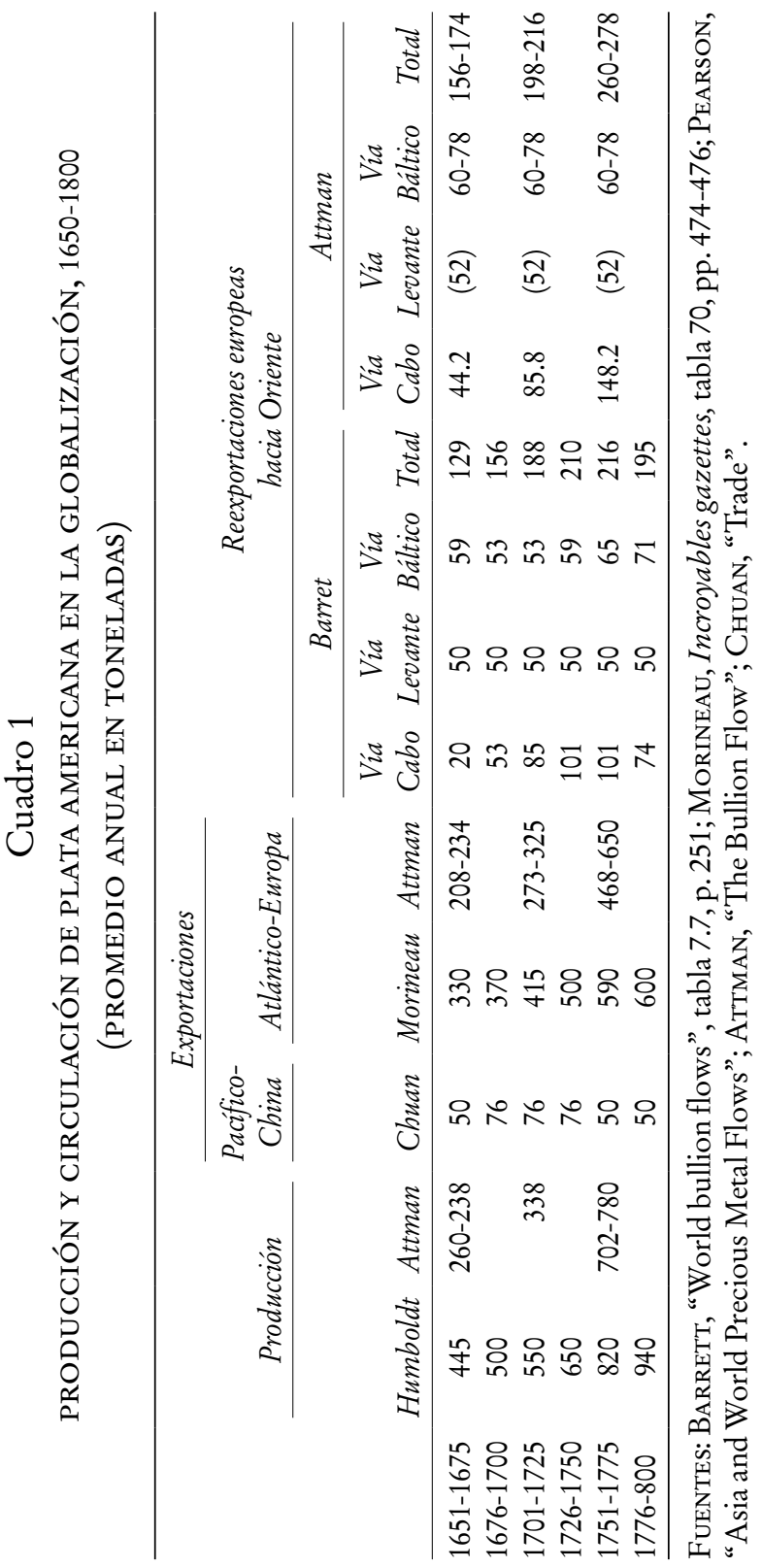


Attman, obtenemos que en los 25 años comprendidos entre 1651 y 1675 , llegaron a España entre 208 y 234 toneladas anuales. Para el periodo 1701-1725, de 273 a 325 toneladas, y 468-650 para los años que van de 1750 a $1775 .{ }^{36}$ Las famosas series de Morineau son útiles para contemplar el comercio entre América y Europa incluido el contrabando. Según Morineau, de 1676 a 1700 ingresaron un promedio anual de 370 toneladas de plata a Europa; entre 1701 y 1725: 415; 1726-1750: 500; 1751-1775: 590, y de 1776 a 1780: 600 toneladas anuales en promedio. ${ }^{37}$

Por su parte, para calcular la plata que se habría exportado hacia China por el comentado eje del Pacífico (considerando plata peruana y mexicana) se tomaron en consideración las estimaciones brindadas por el historiador Chuan Hang Sheng. Dichas cifras, que también se muestran en nuestro cuadro, parecen contemplar el notable contrabando realizado por el eje transpacífico, distanciándose de las tendencias mínimas que ofrecen reconocidos trabajos. Ward Barrett ha estimado para el siglo xviII un promedio anual de exportación que no excedía los 800000 pesos. ${ }^{38} \mathrm{El}$ cálculo de Barrett se apoyó en las observaciones de Humboldt en su Ensayo político, según las cuales “desde finales del siglo xvi a 1803, han fluido de Acapulco a Filipinas un promedio anual de 600000 pesos al año". ${ }^{39}$ Barrett llegó a sugerir una exportación anual por el eje transpacífico de 15-21 toneladas de plata en promedio. Por su parte, según Carmen Yuste, el promedio anual cargado en el galeón rondaría entre las 30-33 toneladas. ${ }^{40}$ Ahora bien, contemplando el gran fenómeno de contrabando que se practicó por el eje, Chuan Hang Sheng, como Bonialian, estiman salidas hacia las islas Filipinas de un

\footnotetext{
${ }^{36}$ Attman, "The Bullion Flow”, p. 68.

${ }^{37}$ Morineau, Incroyables gazettes, cuadro 70, pp. 474-476.

${ }^{38}$ BARRETT, "World bullion flows", cuadro 7.6, pp. 248-249.

${ }^{39}$ Нumboldt, Ensayo político, p. 437.

${ }^{40}$ Yuste, El comercio.
} 
promedio anual de 2 a 4000000 de pesos en plata americana. ${ }^{41}$ Existen tendencias más elevadas, como las sugeridas por Flynn y Giráldez, para quienes entre 1581 y 1700 el promedio anual rondó los 5500000 pesos. ${ }^{42} \mathrm{Al}$ menos para ciertos años precisos de finales del siglo XVI, cuando el auge en la producción de plata de Potosí vivía sus mejores épocas, dicha cifra parece una exageración. Si aceptamos a priori aquella cifra de 2 a 4000000 de pesos anuales se llegaría a la conclusión de que se exportaron hacia Oriente un promedio anual de entre 51 y 102 toneladas en plata americana; prácticamente el doble de lo que mencionan los registros oficiales. De tal manera, el flujo metalífero directo entre América y China por el eje transpacífico alcanzó magnitudes considerables, que en varias coyunturas precisas (1590-1630 y 1680-1740) pusieron en serio riesgo los envíos de plata hacia Europa por los canales trasatlánticos.

Ahora bien, retomemos el frente europeo. Según Gunder Frank, más de la mitad de la plata americana ingresada a Europa se reexpedía hacia los mercados del Oriente, en particular hacia la India y China. ${ }^{43}$ La premisa se confirma con las estimaciones de Barrett y Attman que aparecen en el cuadro 1. China fue, durante los siglos XVI, XVII y gran parte del XVIII, el depósito o almacén mundial de la plata americana. Básicamente fueron tres las rutas de la plata que conectaron a Europa con la India y China: a) la ruta del Báltico que iba por el norte de Rusia; b) el derrotero del Levante o por las costas septentrionales de África, ambas trazadas previamente por el Mediterráneo, que convergían en las costas occidentales de la India para continuar su trayecto hacia China por las costas de Malabar, y c) la vía del Cabo de Buena Esperanza, ruta más utilizada durante la globalización temprana. Las compañías europeas del Oriente se ubica-

${ }^{41}$ Chuan, “Trade”, p. 3; Bonialian, El Pacífico hispanoamericano.

42 Flynn y Giráldez, “China”.

43 Frank, ReOrient, pp. 143-150. 
ron como los agentes económicos principales que posibilitaron todo este gran movimiento de bienes y metales entre Europa y el Oriente. Las compañías orientales de los ingleses, franceses, holandeses, y en menor medida dinamarqueses, instituciones mercantiles con gran poder político en sus enclaves del Oriente (Batavia, Coromandel, Madrás, Goa, Bengal, Siam, Malaca, Java y Cantón), fueron el medio para llevar la plata americana hacia los mercados de la India y China. ${ }^{44}$

Veamos el movimiento monetario de estos flujos. La tendencia la vemos reflejada en el cuadro 1 y demuestra que al menos desde la segunda mitad del siglo XvII el espacio oriental logró concentrar más cantidad de plata americana de la que terminó circulando en los propios mercados europeos, luego de su reexportación hacia Oriente. Si incorporamos el circuito transpacífico la diferencia se acentúa aún más. La explicación tradicional intenta comprender el fenómeno en función del déficit continuado de la balanza comercial europea en su comercio con Oriente. Europa poco tenía para ofrecer a cambio de los muy estimados artículos de seda, de algodón de la India, las especias asiáticas o el té. La moneda de plata mexicana y peruana resultó ser el medio de cambio por excelencia para que los europeos adquirieran artículos orientales de gran capacidad de consumo en los mercados europeos. Nos referimos al té, las especias y textiles de seda y algodón.

Una segunda interpretación ubica el acento en las causas de la silverization asiática en razones derivadas del propio plano de la circulación monetaria internacional, en particular de las oportunidades que ofrecía el sistema monetario del imperio chino de los Ming a las economías europeas. La depreciación del valor del metal en Europa en relación con el oro, fenómeno condicionado por la inflación registrada en los mercados europeos a partir del siglo xvi a raíz de la incesante importación de

${ }^{44}$ WiLls, “European Consumption”, pp. 133-147. 
la plata desde América. En segundo término, la atracción de plata hacia Asia se explica por el fenómeno inverso, es decir, por una notable alza en la cotización de la plata en China en relación con el patrón oro. Desde el siglo xvi hasta mediados del xviII se habría registrado un más alto valor de la plata en China, en la India e incluso en Persia que en la propia Europa. Con un cambio ventajoso y con la disponibilidad de plata, los comerciantes europeos tenían la oportunidad de comprar un mayor volumen de mercancías asiáticas que europeas. A inicios del siglo xvi la relación oro-plata era de 1:6 en China, en el reino hindú de 1:8, y en Persia 1:10 mientras que en Europa la tasa de cambio giraba alrededor de 1:12. En 1590, el cambio en Cantón oscilaba entre 1:5.5 y 1:7, mientras que en España era de 1:12.5 o 1:14. ${ }^{45}$ En la primera mitad del siglo xviII, China continuaba con un cambio más ventajoso que Europa; el reino asiático registraba una cotización de 1:10 o 1:11 y Europa de 1:15. Era sólo cuestión de operar de acuerdo al arbitraje monetario, al mercado mundial propiamente monetario, para lograr extraer un buen beneficio en los diferenciales de precios. Otro factor fundamental que explicaría la llegada masiva de plata americana a China estaría en las políticas monetarias y fiscales del Estado chino. En un contexto de auge demográfico, amplios sectores sociales, como campesinos, artesanos y comerciantes, estaban obligados a pagar los impuestos en plata. La monetización que registraba el sector privado de la economía asiática se fue transmitiendo al sector público. Así, desde finales del siglo xvi, el reino de China comenzó a funcionar con el patrón dominante de la moneda de plata en su economía interna. El proceso chino de "silverización" fue acompañado por una clara política económica de rebajar los costos de producir papel moneda para los intercambios internos. ${ }^{46}$

\footnotetext{
${ }^{45}$ Flynn y Giráldez, “Cycles”, pp. 393-395.

46 Flynn y Giráldez, “Cycles”, p. 419, y "Money”.
} 
Ahora bien, si observamos los circuitos comerciales y de metales preciosos desde la perspectiva de los actores, se revelan otras facetas y características de su funcionamiento. Habría que prestar atención a la agencia de los americanos. Lo que hizo entrar a los metales a los circuitos globales no fue la iniciativa china, no obstante que gran parte de los metales terminaron en el Imperio del Medio. El sistema fiscal español y, ante todo, el comercio privado apoyado en el consumo americano de productos europeos y asiáticos resulta clave. La dinámica consumidora se estableció inmediatamente después de la conquista, pues las nuevas élites de los territorios hispanoamericanos requerían, para su estatus, para su seguridad y para recrear sus costumbres, productos que no se producían en América. ${ }^{47}$ Así, la América conquistada engendró una demanda de productos de importación de diferentes partes del globo. Para adquirirlos, es decir, para poder importar, fue imprescindible exportar. Sin embargo, como consecuencia del aislamiento de la masa continental euroasiática africana, los productos americanos no se conocían en el Viejo Mundo y, por lo tanto, no tenían ni demanda ni precio. Los españoles enfrentaban, de esta suerte, un problema económico que requería una solución inmediata, y la encontraron en los metales preciosos. Expropiaron a los indígenas su oro acumulado a lo largo de los siglos y explotaron los placeres de oro. Pronto descubrieron las primeras minas argentíferas, por ejemplo, en 1545 los yacimientos del Cerro Rico de Potosí en los Andes y Zacatecas en la Nueva España. La minería fue emprendida por los intereses de consumo privados de los españoles en América, y la plata pasaría a ser la mercancía más importante de exportación hispanoamericana.

47 Hausberger, “La economía”, pp. 52-55. 
Los cálculos que se han efectuado confirman que la mayor parte de la plata salió de América por el comercio privado. De los casi 500000000 de pesos que entre 1503 y 1660 llegaron a España, sólo algo más de la cuarta parte pertenecía a la Real Hacienda, disminuyéndose el porcentaje con el paso del tiempo: de 1503 a 1540 fue $52.5 \%$, de 1717 a $173814 \%$, y de 1748 a 1778 no más de $9 \%{ }^{48}$ En la última década del siglo XviII, en el contexto del reformismo borbónico, según Javier Cuenca Esteban, los envíos de la corona volvieron a crecer y alcanzaron $37.6 \%$ en $1796,{ }^{49}$ probablemente debido al esfuerzo de la metrópoli de sacar dinero de sus colonias para financiar sus guerras. En las exportaciones de plata a Manila, sólo tomando en cuenta los números oficiales, entre 1591 y 1640, 59.6\% era plata privada, $\mathrm{y}$ entre 1581 y 1700 fue $69.8 \% .{ }^{50}$ Desde luego, por el contrabando no registrado en las estadísticas oficiales, el peso de los envíos privados debe haber sido mayor de lo que las cifras citadas indican. Por ejemplo, llama la atención que en la segunda mitad del siglo XVII las importaciones de plata en España bajaran 90\%, mientras que las exportaciones de textiles a América se quintuplicaran y las de aceite de oliva se triplicaran. ${ }^{51}$ Fernando Serrano Mangas cita el caso de un galeón naufragado en el Caribe, con una carga registrada de cerca de medio millón de pesos, del cual los buceadores del equipo de rescate sacaron nada menos que $11000000 .^{52} \mathrm{La}$ informalidad comercial por el eje transpacífico parece haber sido tanto o más importante a la practicada por el Atlántico. Ya hemos advertido en páginas previas que si bien se autorizaba una salida de plata hacia Filipinas por 1000000 de pesos por año, las fuentes no oficiales hacen referencia a que los

\footnotetext{
${ }^{48}$ Hamilton, American Treasure, p. 34; García-Baquero González, La carrera de Indias, p. 231.

49 Cuenca Esteban, "Statistics", p. 330.

50 Bonialian, El Pacífico p. 209; TePAske, “New World Silver”, pp. 444-445.

51 Oliva Melgar, "La metrópoli”, pp. 32-35.

52 Serrano Mangas, Naufragios, pp. 69-70.
} 
galeones de Manila cargaban en sus bodegas al salir de Acapulco de 3 a 4000000 de pesos cada año. ${ }^{53}$

Las listas existentes de productos importados muestran que, efectivamente, se traían sobre todo bienes de uso cotidiano. En 1524, por ejemplo, La Trinidad transportaba la siguiente carga a Santo Domingo: $7560 \mathrm{l}$ de aceite de oliva, 38501 de vino, $276 \mathrm{~kg}$ de jabón, $257 \mathrm{~kg}$ de cera, $362 \mathrm{~m}$ de ruan, $278 \mathrm{~m}$ de terciopelo, $20 \mathrm{~m}$ de paños veinticuatrenos, 159 camisas, 128 pares de zapatos de cuero, 8072 clavos de hierro, 600 herraduras y 45 resmas de papel. ${ }^{54}$ Este panorama no cambiaría durante toda la época colonial, y prevalecía también en el eje Pacífico. Pedro León Portocarrero, el reconocido judío mercader de Lima, escribía en 1620 que la Ciudad de los Reyes era un centro consumidor de bienes suntuosos de China y de Europa que se equiparaba a las grandes ciudades europeas de la época. ${ }^{55}$ Los altos costos del transporte usuales en la época limitaron la gama de productos comerciables de larga distancia a los de alto valor y reducido peso y volumen. Para los productos que no cumplieron con estos requisitos, paralelamente a la importación nació una nueva estructura artesanal y manufacturas, sobre todo los obrajes que elaboraban textiles sencillos.

\section{INDUSTRIALIZACIÓN}

Ahora bien, ¿la circulación mercantil constituyó en sí una verdadera globalización? Conforme a nuestra definición inicial sí, porque los enlaces comerciales, fueran formales o informales, permitieron que las economías internas de cada bloque continental estuvieran en relación sostenida. Para reforzar el

53 Chuan, “Trade”; Bonialian, El Pacífico, pp. 212-225.

54 Pieper, “Die Exportstruktur”.

55 Bonialian, China en la América, pp. 115-116 Para el siglo XviII, véase LAmikiz, "Patrones de comercio". 
argumento, se puede recalcar la relevancia de las conexiones para el desarrollo global. En este apartado queremos presentar algunas ideas sobre el papel de América Latina en la creación de las condiciones necesarias para el arranque de la industrialización europea. Aunque siempre había intentos de explicar la industrialización en un contexto globalizado, ${ }^{56}$ a América Latina nunca se le ha prestado mucha atención.

¿En qué medida fue la industrialización un desarrollo insertado en las ya existentes relaciones globales, o más bien fue un fenómeno específicamente británico o europeo? En un trabajo más reciente, Robert C. Allen ha destacado los elevados costos laborales vigentes en Gran Bretaña en los momentos del arranque de la industrialización como una de las precondiciones claves para hacer rentable la mecanización de los procesos de producción. ${ }^{57}$ Los salarios se beneficiaban, sobre todo, del desarrollo de las manufacturas textiles, las cuales mostraban prosperidad mucho antes de la industrialización. Para ello, el mercado británico, con su comparativamente elevada fuerza de compra, fue de gran importancia. Por sí solo, hubiera sido demasiado pequeño para rentabilizar el aumento de la producción y las inversiones necesarias. Es aquí donde entra el papel de la exportación. Para poder exportar se requería un extranjero solvente que comprara la creciente oferta británica. En otras palabras: el mundo fuera de Gran Bretaña puede que haya sido atrasado y arcaico, pero sin el potencial de compra que representaba, a la incipiente industria inglesa probablemente le hubiera resultado difícil mantener su ritmo de crecimiento.

En el siglo XVIII, las exportaciones británicas crecieron marcadamente y, después de 1770, este desarrollo se aceleró. Según

${ }^{56}$ Por ejemplo, Inikori, Africans, quien reexamina con nuevas evidencias la vieja hipótesis de Eric Williams, Capitalism E Slavery. Pomeranz, The Great Divergence, cap. 3, discute la importancia de las plantaciones coloniales para la economía occidental.

${ }^{57}$ Allen, The British Industrial Revolution. 
Price, en 1700 alrededor del $24 \%$ de la producción se exportaba, y hacia 1760 ya era de $35 \%$. En algunos sectores estos valores eran incluso más altos: en 1770-1774, 40\% del latón, cerca de $42 \%$ del hierro forjado, y entre 45 y $50 \%$ de los tejidos fueron al extranjero. ${ }^{58}$ Entre $1699-1701$ y $1772-1774$, las exportaciones manufactureras muestran un crecimiento de $119 \%,{ }^{59} \mathrm{y}$, entre 1787-1789 y 1816-1820, las exportaciones totales se incrementaron $184 \%$; las de telas de algodón aumentaron en este periodo $1874 \%$ y constituyeron en $1816-182063.4 \%$ del total. ${ }^{60}$

\section{Cuadro 2}

DESTINO REGIONAL DE LAS EXPORTACIONES BRITÁNICAS (SIN REEXPORTACIONES Y SIN FLUJOS DE METALES PRECIOSOS)

\begin{tabular}{lrrrrrrr}
\hline & $1699-$ & $1722-$ & $1752-$ & $1772-$ & $1787-$ & $1797-$ & $1816-$ \\
& 1701 & 1724 & 1754 & 1774 & 1789 & 1815 & 1820 \\
\hline $\begin{array}{l}\text { Europa } \\
\text { continental }\end{array}$ & $82.6 \%$ & $78.2 \%$ & $61.8 \%$ & $42.6 \%$ & & & \\
$\begin{array}{l}\text { Europa y } \\
\text { Levante }\end{array}$ & & & & & & & \\
$\begin{array}{l}\text { Irlanda } \\
\text { India y Lejano }\end{array}$ & $2.2 \%$ & $1.6 \%$ & $3.4 \%$ & $5.9 \%$ & $8.8 \%$ & $9.8 \%$ & $8.2 \%$ \\
$\begin{array}{l}\text { Oriente } \\
\text { Asia }\end{array}$ & $2.9 \%$ & $2.3 \%$ & $10.0 \%$ & $8.1 \%$ & & & \\
$\begin{array}{l}\text { América y } \\
\text { África }\end{array}$ & $12.3 \%$ & $17.9 \%$ & $24.8 \%$ & $43.4 \%$ & $35.7 \%$ & $53.6 \%$ & $44.9 \%$ \\
$\begin{array}{l}\text { América } \\
\text { (incl. E.U.) }\end{array}$ & & & & & & & \\
E.U. & & & & & $32.1 \%$ & $51.7 \%$ & $44.0 \%$ \\
África & & & & & $14.4 \%$ & $21.1 \%$ & $17.2 \%$ \\
\hline
\end{tabular}

Fuentes: Findlay y O’Rourke, Power, cuadro 5.4 (para 1699-1774); Cuenca Esteban, “Comparative patterns”, cuadro 2.3 (para 1787-1820).

${ }^{58}$ Price, “The Imperial Economy”, pp. 98-99.

59 Findlay y O’Rourke, Power, p. 260.

${ }^{60}$ Cuenca Esteban, "Comparative patterns", p. 43. 
Pero, ¿a qué mercados se destinaban estas mercancías? Desde luego, por la cercanía, las ventas europeas siempre fueron de gran importancia, aunque desde el siglo XvII oscilaban bastante y sufrieron mucho a raíz del bloqueo continental impuesto entre 1806 y 1814. Según la información resumida en el cuadro 2, vemos que conforme estaba avanzando el siglo xviII, la importancia de los mercados europeos, aunque poderosa, estaba disminuyendo y la de ultramar, creciendo. Sobre todo, las ventas en América, después de derrumbarse brevemente como consecuencia de la guerra de independencia de Estados Unidos, crecían y rebasaban a las del continente europeo durante las guerras napoleónicas. El sur y este de Asia, en cambio, regiones a las que se presta tanta atención en la historia global actual, eran de importancia secundaria. Al Oriente siguieron fluyendo sobre todo los metales preciosos amonedados. ${ }^{61}$ Los algodones de la India eran de calidad superior y, además, se veían favorecidos por costos salariales mucho más bajos. Constituían una seria competencia para los empresarios británicos, la que sólo en los años noventa del siglo xviII empezaría a bajar. Por lo pronto, fue enfrentada con diversas medidas proteccionistas y, luego, con una creciente racionalización de los procesos productivos. La importancia comercial de los productos asiáticos en Europa no se puede tratar en detalle, mas hay que destacar que su reexportación produjo al comercio británico altas ganancias. Además, muchas telas hindúes entraron a las cadenas de producción británicas y fueron refinadas antes de su venta final. En particular, con el estampado de tejidos blancos con diseños de moda, los talleres ingleses hacían un pingüe negocio. ${ }^{62}$ Los mercados más importantes se ubicaban, entonces, en el espacio atlántico.

¿Dónde quedó América Latina? Primero hay que señalar que las importaciones que las dos monarquías ibéricas recibían

\footnotetext{
${ }^{61}$ Bowen, "Bullion".

${ }^{62}$ Riello, Cotton, pp. 149-151.
} 
de sus posesiones en el Nuevo Mundo siguieron siendo importantes, lo que se confirma al compararlas con la situación británica. Hacia 1700, Inglaterra y Gales importaban $1956000 £$ de territorios extraeuropeos; de ellos, 59\% de América; para 1750 este monto había subido a 3505000 \& (67\% de América), y en 1772-1773 fueron 6803000 \& (66.5\% de América). En 1789-1790 llegaron a Gran Bretaña bienes con valor de cerca de $3256000 £$ de Asia y $5398000 £$ (62.4\% del total) desde sus colonias americanas y Estados Unidos, es decir, en total 8654000 £..$^{33}$ Siguiendo los datos de Cuenca Esteban, a los puertos españoles llegaron, entre 1782 y 1789, importaciones con valor de 36218100 pesos al año de sus virreinatos americanos (de ellos, 21568300 pesos, o $59.6 \%$, en metales preciosos) ${ }^{64}$ Con las malicias del tipo de cambio esto resulta en una importación anual de entre $5.4 \mathrm{y}$ 8.2 millones de libras, de ellas de 3.2 a 4.9 en oro y plata. ${ }^{65}$ De esta suerte, las importaciones españolas de América se mantenían por encima de las que el Reino Unido recibía de sus colonias americanas, incluso Estados Unidos. No muy atrás estaban las exportaciones brasileñas a Portugal: en el siglo XviII consistían principalmente en oro, ascendiendo anualmente en promedio de $3650000 £$ entre 1711 y 1760 , a $3900000 £$ entre 1761 y 1780 , y a $3250000 £$ entre 1781 y $1810 .{ }^{66}$ Aunque estas importaciones apenas fomentaban la industrialización en España y Portugal, queda manifiesto que en la península Ibérica sobraban medios en forma de plata y oro para hacerse de una parte importante de la oferta europea.

El Reino Unido mantuvo un considerable intercambio con los imperios ibéricos, aunque el comercio directo con Hispanoamérica estaba vetado por el monopolio español. Pero había otras vías por las que los productos extranjeros pudieron llegar

\footnotetext{
${ }^{63}$ Mitchell, British Historical Statistics, p. 496.

${ }^{64}$ Cuenca Esteban, "Statistics of Spain's Colonial Trade”, pp. 345-347.

${ }^{65}$ Véase nota 86.

${ }^{66}$ INIKORI, Africans, p. 181.
} 
a Hispanoamérica. En primer lugar, una porción de la mercancía vendida legalmente en España fue reexportada al Nuevo Mundo. A mediados de los años noventa del siglo XviII (sin las reexportaciones), $11.5 \%$ de las exportaciones de productos manufactureros británicos al espacio atlántico fueron a la península Ibérica. ${ }^{67}$ En la época de las reformas borbónicas, los españoles lograron aumentar, por lo menos oficialmente (porque la reetiquetización de productos extranjeros era práctica frecuente), la tasa de productos domésticos en sus exportaciones a América, de un poco por debajo de $40 \%$, en $1776-1778$, a $52.4 \%$ en 1788-1792. No obstante, en un ámbito de crecimiento comercial sostenido, también las reexportaciones de productos extranjeros - entre ellos los británicos - se incrementaron mucho, llegando al máximo de 14.6 millones de pesos en $1784-1786 .{ }^{68}$ Además, se practicaba un activo contrabando desde el Caribe y Brasil con las posesiones españolas. Muchos productos británicos llegaron a Hispanoamérica por Estados Unidos, o en barcos estadounidenses, sobre todo cuando durante las guerras napoleónicas esta conexión fue legalizada como comercio neutral.

Adrian Pearce ha estimado las exportaciones británicas a Hispanoamérica (las directas y las realizadas vía España, el Caribe británico y Brasil) en 500000 £ hacia 1700 (10.8\% de las exportaciones totales), en los años treinta, en $1300000 £$ en los años sesenta (cerca de 15\% de las exportaciones totales) y aproximadamente en $2000000 £$ a mediados de los noventa. Más adelante tales estimaciones se vuelven difíciles, pero Pearce considera factible un continuado crecimiento a entre 3 y $4000000 £$ (por lo menos 6\% de las exportaciones británicas), lo que sería

${ }^{67}$ Inikori, Africans, pp. 512, 514 (he calculado, conforme a la información de la p. 522, que 55\% de las exportaciones al sur de Europa iba a España y Portugal).

${ }^{68}$ Cuenca Esteban, “Statistics”, p. 333. 
considerablemente más de lo que habitualmente se ha pensado. ${ }^{69}$ En otras palabras, el vínculo con América posibilitó a España comprar grandes cantidades de mercancías europeas, entre otras, británicas, y con Portugal pasó lo mismo. Desde finales del siglo XVII hasta la segunda mitad del XvIII, los ingleses ganaron enormes sumas en el territorio lusitano. Entre 1758 y 1763, Gran Bretaña importaba en promedio $764612 £$ en oro al año desde Brasil, en cuyo intercambio surtía principalmente textiles. ${ }^{70}$

De la liquidez que América proporcionó a los poderes ibéricos, se aprovechaba la fuerza de compras de toda Europa. Por ejemplo, si bien Francia, el abastecedor principal de España con productos manufactureros, ganaba enormes sumas de plata, su balance comercial era muy negativa con Inglaterra. De esta suerte, Jacques Accarias de Serionne, en 1767, lo consideró una feliz circunstancia "par le bien general" que hubiera en Europa naciones que procuraban lograr una ventajosa balanza comercial mediante la explotación minera y otras dedicándose a las manufacturas. ${ }^{71}$ En suma, las ganancias logradas en la península Ibérica por diferentes regiones europeas se tradujeron en ingresos de la industria británica, pues fortalecían la fuerza de compra del continente.

Igualmente dinámico fue el papel de Norteamérica. Las colonias británicas y luego Estado Unidos a lo largo del siglo xviII tenían un déficit con Gran Bretaña, el que por ejemplo entre 1770 y 1774 alcanzó casi $1300000 £$ al año. ${ }^{72}$ Pero se compensaron en otras partes. Los territorios angloamericanos mantenían un lucrativo comercio con el Caribe y con España, en el que ganaban considerables cantidades de plata, es decir, dinero. Ya en

\footnotetext{
69 Pearce, British Trade, pp. 230-249; Cuenca Esteban ha considerado las estimaciones de Pearce como conservadoras y cree probable un comercio aún más amplio, sobre todo por E.U.; Cuenca Esteban, "British 'Ghost' Exports”.

70 Carrara, “La producción”, pp. 257-258.

71 SÉRIONNE, Les intérêts, vol. 1, p. 68.

72 PRICE, “The Imperial Economy”, p. 103.
} 
el siglo xvir, la pesca y el comercio de bacalao constituyeron un constante flujo de plata español hacia Inglaterra y las colonias en Nueva Inglaterra. ${ }^{73}$ Con el sur de Europa (donde el destino más importante fue España), el comercio norteamericano entre 1768 y 1772 tuvo un superávit anual de $456600 £^{74}$ Igualmente activos, aunque por lo general ilegales, eran los negocios de los angloamericanos con los españoles en América. Durante las guerras a finales del siglo xviII fueron intermitentemente permitidos por la Corte de Madrid, con la denominación de 'comercio neutral', para contrarrestar el cierre de las conexiones trasatlánticas. Así los traficantes estadounidenses se convirtieron en exitosos intermediarios que canalizaban cada vez más productos británicos a los territorios españoles. Además, vendían también a las plantaciones caribeñas cantidades importantes de bacalao. Un destino significativo fue Cuba. Hay que considerar, además, que Hispanoamérica sólo recibió parte de los esclavos requeridos directamente desde África; la otra parte la recibía mediante reexportaciones de las posesiones caribeñas de los otros poderes o desde Brasil. Estados Unidos, de esta suerte, introdujo crecientes porciones de los metales hispanoamericanos en el comercio global. El dinero que ganaban les permitió aumentar su fuerza de compra de productos industrializados británicos.

Estos negocios pudieron prosperar ante todo porque en el Caribe español había mucho dinero enviado desde México para cubrir los costos de la defensa y para financiar el monopolio del tabaco. En el quinquenio de 1720-1724, desde la Nueva España, la Real Hacienda inyectó casi 0.9 millones de pesos de plata al año al Caribe (mientras que remitió sólo 0.65 millones a España). Estas cantidades oscilaban según las exigencias de las numerosas guerras, pero a la larga aumentaron enormemente: de los

${ }^{73}$ Lydon, “The Massachusetts Fish Trade”. También CARTer et al. (eds.), Historical Statistics, cuadro Eg, pp. 343-355.

74 Price, "The Imperial Economy", p. 103. 
ingresos fiscales, en 1795-1799 fluyeron 4.82 millones de pesos al año al Caribe (y 3.17 millones a España). Además, se envió dinero a Cuba para financiar la compra de las hojas de tabaco de los cultivadores. En 1723, fueron 200000 pesos, hacia finales de siglo, $750000 .^{75}$ También el comercio hispanoamericano despachó dinero al Caribe británico. Entre 1792-1795, fueron unos 172000 pesos de plata al año (aproximadamente $40 \%$ de sus exportaciones a la región, que abarcaban, además, mulas, caballos y algodón). ${ }^{76}$

En suma, los imperios ibéricos siguieron cumpliendo con una función central en el mantenimiento de los circuitos globales y, sobre todo, abriendo los mercados consumidores europeos para el desarrollo británico en camino a la industrialización. Tenían un déficit comercial con prácticamente todos los otros países y formaban un mercado nada despreciable del que las industrias europeas se podían servir "comme un bien public". ${ }^{77}$ Sus metales preciosos no sólo aseguraron la liquidez del comercio del Occidente con Asia, sino también la solvencia con el Reino Unido. Aunque los británicos se preocuparan de la constante evasión de dinero al Oriente, se compensaban con las ganancias que hacían en Europa continental y en Norteamérica. Gran parte de este dinero se logró mediante las reexportaciones de productos asiáticos y caribeños. ${ }^{78}$ Pero fue el superávit con el mundo ibérico el que sostuvo tanto el sistema monetario como el comercial.

75 Marichal, Bankruptcy, pp. 38, 269.

76 Pearce, British Trade, pp. 271-275.

77 Sérionne, Les intérêts, vol. 1, pp. 43, 132.

78 Según César Moreau, en 1787, el déficit comercial de Gran Bretaña alcanzó 26.2 millones, sin las reexportaciones, y sólo 2.5 millones, tomándolas en cuenta; "Examen impartial du commerce de la Grand e Bretagne avec toutes les parties du monde [...], par César Moreau, 1828”, (http://gallica.bnf.fr/ ark:/12148/bpt6k311298v.r=/22cesar/20moreau/22?rk=21459;2). Según series más modernas, el déficit, sin reexportaciones, en 1789-1790 de 27.5 millones de pesos, se convirtió en un superávit de 8.4 millones, con las reexportaciones; Mitchell, British Historical Statistics, p. 496. Según Arnould, en 1787, el 


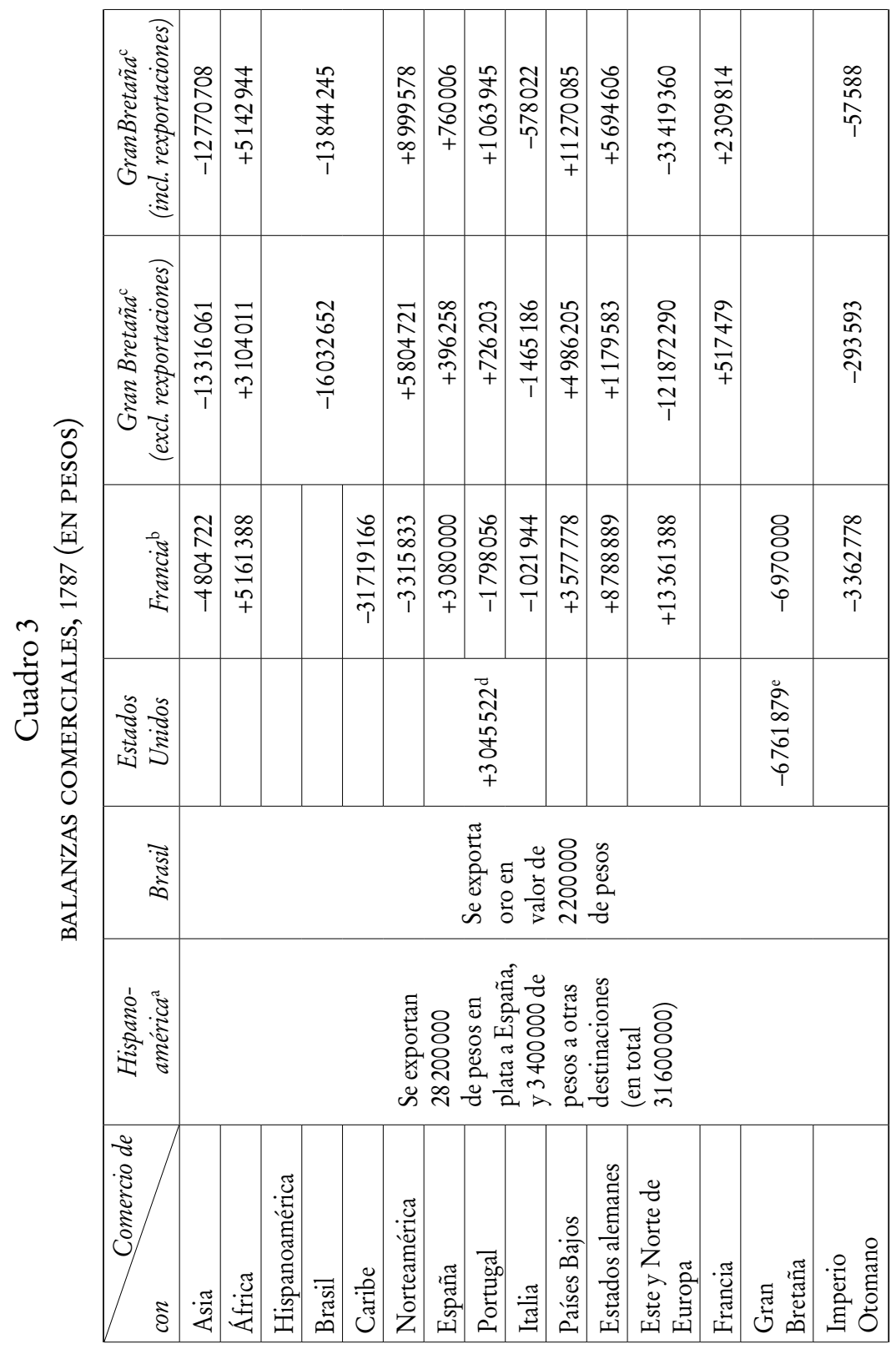




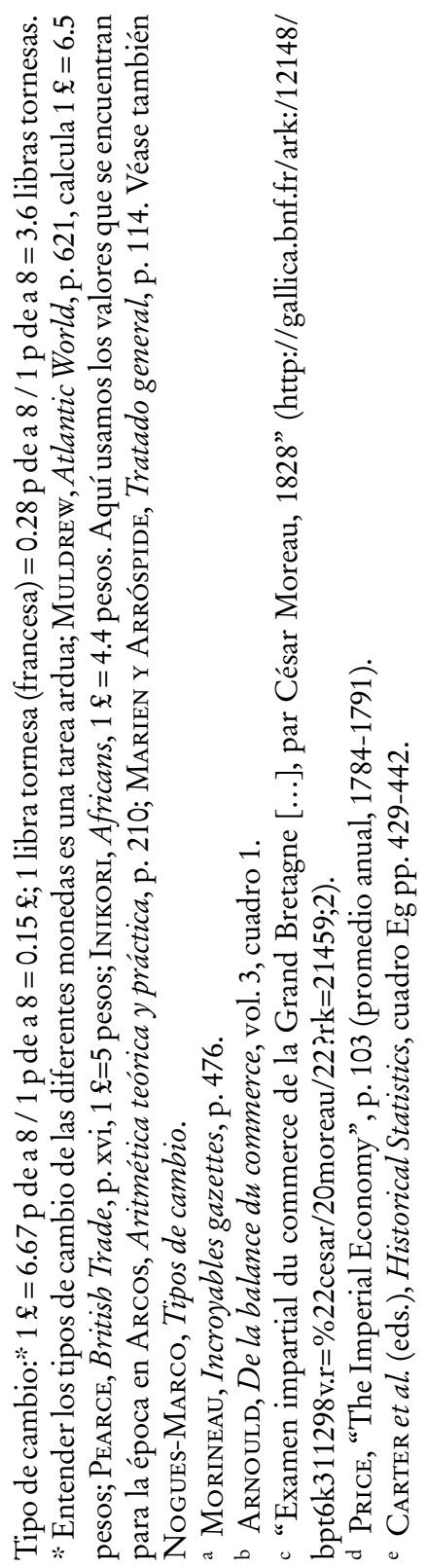


En el cuadro 3, hemos reunido cálculos sobre las balanzas comerciales para mayor claridad. Hay que subrayar que cada uno de los números y series se presta a debate. En su mayoría sólo reflejan las contadurías oficiales y no toman en cuenta el comercio ilícito. Tampoco incluyen el comercio directo entre diferentes regiones extraeuropeas controlado por los europeos, ni tampoco el comercio de esclavos; así, según Arnould, entre 1785 y 1787, los franceses vendieron en promedio 30000 esclavos africanos en sus posesiones caribeñas, con un valor de 10.8 millones de pesos, monto que no se refleja en el cuadro. ${ }^{79}$ Las regiones, usadas por los autores consultados, son delimitadas de diferente manera. Además, hay que destacar que la plata y el oro fluían por Europa y el mundo no sólo por el comercio. Arnould, por ejemplo, comentó que en 1787 entraron en posesión francesa desde España 17.4 millones de pesos, y sólo 3.1 millones procedían de las ganancias del comercio bilateral; 4.2 millones fueron recogidos directamente en Cádiz por los barcos de la Compañía Francesa de las Indias Orientales, en su viaje a Asia, y del resto, gran parte llegó a París para saldar la deuda exterior de España (conforme un tratado entre los banqueros parisinos y el Banco de San Carlos, de 1783). ${ }^{80}$ Además, habría que tomar en cuenta el gasto público, el financiamiento de las guerras, la paga de subsidios, los que, por ejemplo, pagó Gran Bretaña a diferentes países del continente. Con todo, creemos que el cuadro sirve para mostrar las tendencias generales. Para permitir la comparación he convertido los datos en pesos.

No se ha tratado aquí de reconstruir cómo los poderes europeos, impulsados por las ideas del mercantilismo, intentaban

déficit comercial de Francia era de 19 millones de pesos; Arnould, De la balance du commerce, vol. 3 , cuadro 2 .

79 Arnould, De la balance du commerce, vol. 1, pp. 300-301.

${ }^{80}$ Arnould, De la balance du commerce, vol. 1, pp. 141-142. Morineau, Incroyables gazettes, p. 466, dice que en 1787 llegaron 9.7 millones de pesos españoles a Francia. 
acaparar cantidades de metales preciosos y promover balanzas de comercio positivas, como ya lo ha intentado resumir, por ejemplo, Werner Sombart. ${ }^{81}$ Más bien hemos querido mostrar cómo los metales preciosos americanos dieron una nueva fuerza de compra no sólo a los imperios ibéricos, sino, al distribuirse por el globo, a muchas partes del mundo, en primer lugar a toda Europa. La creación del mercado americano a partir de la conquista tuvo, de esta suerte, un prolongado efecto multiplicador en el crecimiento industrial y fue una necesaria, aunque por sí sola insuficiente, condición para el avance de la industrialización. Si esta hipótesis se sostiene, confirmaríamos el carácter multipolar de la temprana globalización, la que, sin embargo, tuvo consecuencias divergentes para las regiones que conectaban.

\section{EPÍLOGO}

Ya los arbitristas del siglo xvi habían observado que la abundancia de plata empobreció a España y enriqueció a sus enemigos. Cierto es que no estimulaba el sector productivo, más bien lo contrario. Si en el siglo xviII los metales americanos abastecían con dinero a los mercados necesarios para la industrialización británica, ésta hundió en serios, aunque regionalmente desiguales, problemas a la protoindustria hispanoamericana ${ }^{82} \mathrm{El}$ fenómeno se observa desde la segunda mitad del siglo xviII, con las reformas comerciales borbónicas. En efecto, la flexibilización comercial y la apertura de nuevos puertos al tráfico global permitieron que, fuera de registro o contrabando, los textiles de algodón de Gran Bretaña y de la India (cuyo comercio igualmente fue controlado por los británicos) fuesen consumidos en los mercados hispanoamericanos por diferentes grupos sociales.

${ }^{81}$ Sombart, "Der Kampf”.

${ }^{82}$ Miño Grijalva, El obraje, pp. 385-395, es muy cuidadoso al medir el impacto negativo de las importaciones en la producción latinoamericana. 
Es decir, el patrón de consumo se vio profundamente modificado con la llegada de los navíos de registro a puertos hispanoamericanos que, anteriormente, se encontraban cerrados o con una mínima actividad. De alguna manera, las reformas instauradas por Carlos III para el comercio ultramarino ofrecieron las bases para que hacia finales del siglo xviII y principios del xix los algodones importados predominaran en los mercados consumidores de Hispanoamérica. El derrumbe definitivo del monopolio español a raíz de la independencia reforzaría este proceso, ya en una nueva fase de la globalización. Una nueva etapa de la economía global donde tanto China y la economía asiática como Hispanoamérica perderían el protagonismo que supieron tener en el periodo precedente.

\section{REFERENCIAS}

Alba, Carlos, Marianne Braig, Stefan Rinke y Guillermo Zermeño (coords.), Entre Espacios. Movimientos, actores y representaciones de la globalización, Berlín, Edition Tranvía, Verlag Walter Frey, 2013.

Allen, Robert C., The British Industrial Revolution in Global Perspective, Cambridge, Cambridge University Press, 2009.

Arcos, Fermín de los, Aritmética teórica y práctica, en compendio de las cuentas más usuales y corrientes, tanto para el comercio de los Reynos de Castilla, Aragón. Valencia, Navarra, y Mallorca, como para los de fuera de él, Madrid, Alfonso López, 1786.

Arnould, Ambroise-Marie, De la balance du commerce et des relations commerciales extérieures de la France, dans toutes les parties $d u$ globe [...], París, Buisson, 1791, 3 volúmenes.

Assadourian, Carlos Sempat, "La producción de la mercancía dinero en la formación del mercado interno colonial”, en FlorESCANo (comp.), 1979, pp. 223-292.

Attman, Artur, “The Bullion Flow from Europe to the East: 1500-1800”, en Van Cauwenberghe (ed.), 1989, pp. 65-68. 
Atwell, William S., “Another Look at Silver Imports into China, ca. 16351644”, en Journal of World History, 16 (2005), pp. 467-489.

Barrett, Ward, “World bullion flows, 1450-1800”, en Tracy (ed.), 1990, pp. 224-254.

BAYLY, Christopher A., “'Archaic' and 'Modern' Globalization in the Eurasian and African Arena, ca. 1750-185”, en Hopkins (ed.), 2002, pp. 45-72.

BAYLY, Christopher A., El nacimiento del mundo moderno, 1780-1914, Madrid, Siglo Veintiuno Editores, 2010.

Bernabéu Albert, Salvador y Carlos Martínez Shaw (eds.), Un océano de seda y plata: el universo económico del Galeón de Manila, Sevilla, Consejo Superior de Investigaciones Científicas, 2013.

Bernal, Antonio Miguel, "La carrera del Pacífico: Filipinas en el sistema colonial de la carrera de Indias", en CABrero (coord.), 2004, pp. 485-525.

Bonialian, Mariano, El Pacífico hispanoamericano. Política y comercio en el imperio español, 1680-1784. La centralidad de lo marginal, México, El Colegio de México, 2012.

Bonialian, Mariano, “Geopolítica y comercio colonial. El frustrado eje por el Cabo de Hornos entre España y China”, en Jabrbuch für Geschichte Lateinamerikas, 53 (2016), pp. 4-35.

Bonialian, Mariano, "Comercio y atlantización del Pacífico mexicano y sudamericano. La crisis del lago indiano y del galeón de Manila”, en América Latina en la Historia Económica, 24 (2017), pp. 7-36.

Bonialian, Mariano, China en la América colonial. Bienes, mercados, comercio y cultura del consumo desde México hasta Buenos Aires, México, Argentina, Biblos, Instituto Mora, 2014.

Bonialian, Mariano, “México, epicentro semiinformal del comercio hispanoamericano, 1680-1740”, en América Latina en la Historia Económica, 35 (2011), pp. 5-28.

Bowen, H. V., "Bullion for Trade, War, and Debt-Relief. British Movements of Silver to, around, and from Asia, 1760-1833", en Modern Asian Studies, 44 (2010), pp. 445-475. 
BRAUDEL, Fernand, “Historia y ciencias sociales. La larga duración”, en Escritos sobre historia, México, Fondo de Cultura Económica, 1991, pp. 39-74.

Brewer, John y Roy PORTER (eds.), Consumption and the World of Goods, Routledge, Londres, 1994.

Cabrero, Leoncio (coord.), España y el Pacífico, Legaspi, Madrid, Sociedad Estatal de Conmemoraciones Culturales, 2004, t. I.

Canny, Nicholas y Philip Morgan (eds.), The Oxford Handbook of the Atlantic World, c. 1450-c. 1850, Oxford, Nueva York, Oxford University Press, 2011.

Carmagnani, Marcello, "La organización de los espacios americanos en la Monarquía española (siglos Xvi a XVIII)”, en MAZín y RuIz IbáÑEZ (eds.), 2012, pp. 331-355.

Carrara, Angelo Alves, "La producción de oro en Brasil, siglo XviII", en HaUsberger e IBARRA (coords.), 2014, pp. 251-271.

Carter, Susan B. et al. (eds.), Historical Statistics of the United States. Millennial Edition, Cambridge, Nueva York, Cambridge University Press, 2006.

Chaunu, Pierre, "Veracruz en la segunda mitad del siglo xvi y primera del siglo xvII”, en Historia Mexicana, Ix: 4 (36) (abr.-jun. 1960), pp. 521-557.

Chaunu, Pierre, Historia, ciencia social. La duración, el espacio y el hombre en la época moderna, Madrid, Ediciones Encuentro, 1985.

Chuan, Hang-Sheng, "Trade between China, the Philippines and the Americas During the Sixteenth and Seventeenth Centuries", en FlynN y GiráldeZ (eds.), 1997, pp. 845-853.

Cross, Harry, "South American Bullion Production and Export 1550-1750", en Richards (ed.), 1983, pp. 397-423.

Cuenca Esteban, Javier, "Comparative patterns of colonial trade. Britain and its rivals”, en PRADOs De Escosura (ed.), 2004, pp. 35-66.

Cuenca Esteban, Javier, "Statistics of Spain's Colonial Trade”, 1747-1820: New Estimates and Comparisons with Great Britain", en Revista de Historia Económica, 26: 3 (2008), pp. 323-354. 
Cuenca Esteban, Javier, "British 'Ghost' Exports, American Middlemen, and the Trade to Spanish America, 1790-1819", en The William and Mary Quarterly, 71: 1 (2014), pp. 63-98.

De VRIEs, Jan, “The limits of globalization in the early modern world", en The Economic History Review, nueva serie, 63 (2010), pp. 710-733.

Feldbauer, Peter, Estado da India. Die Portugiesen in Asien 1498-1620, Viena, Mandelbaum, 2003.

Findlay, Ronald, y Levin H. O’Rourke, Power and Plenty: Trade, War, and the World Economy in the Second Millennium, Princeton, Princeton University Press, 2007.

Florescano, Enrique (comp.), Ensayos sobre el desarrollo económico de México y América Latina (1500-1975), México, Fondo de Cultura Económica, 1979.

FlynN, Dennis O. y Arturo Giráldez (eds.), Metals and Monies in an Emerging Global Economy, Aldershot, Variorum, 1997.

Flynn, Dennis O. y Arturo Giráldez, “China and the Manila Galleons”, en Latham y KaWaKaTsu (eds.), 1999, pp. 71-90.

Flynn, Dennis O. y Arturo Giráldez, "Money and Growth without Development. The Case of Ming China”, en Latham y Kawakatsu (eds.), 1999, pp. 199-215.

Flynn, Dennis O. y Arturo Giráldez, “Cycles of Silver. Global Economic Unity through the Mid-eighteenth Century", en Journal of World History 13: 2 (2002), pp. 391-427.

Flynn, Dennis O. y Arturo Giráldez, "Path Dependence, Time Lags and the Birth of Globalisation. A Critique of O'Rourke and Williamson", en European Review of Economic History, 8 (2004), pp. 81-108.

Flynn, Dennis O. y Arturo Giráldez, "Los orígenes de la globalización en el siglo Xvi”, en Hausberger e IbARra (coords.), 2014, pp. 29-76.

Frank, André Gunder, ReOrient: Global Economy in the Asian Age, Berkeley, University of California Press, 1998. 
García-Baquero González, Antonio, La carrera de Indias. Suma de contratación y océano de negocios, Sevilla, Sociedad Estatal para la Exposición de 1992, Algaida, 1992.

Hamilton, Earl J., American Treasure and the Price Revolution in Spain 15001650, Cambridge, Harvard University Press, 1934.

Hausberger, Bernd, La Nueva España y sus metales preciosos. La industria minera colonial a través de los 'libros de cargo y data' de la Real Hacienda, 1761-1767, Fráncfort, Madrid, Vervuert, Iberoamericana, 1997.

Hausberger, Bernd, “La economía novohispana, 1519-1760”, en KunTz FICKER (coord.), 2010, pp. 41-170.

Hausberger, Bernd, “Acercamientos a la historia global”, en Alba, Braig, Rinke y ZERMEÑo (coords.), 2013, pp. 83-98.

Hausberger, Bernd y Antonio Ibarra, "Introducción: oro y plata en los inicios de la economía global”, en Hausberger e IbarRa (coords.), 2014, pp. 9-27.

Hausberger, Bernd y Antonio Ibarra (coords.), Oro y plata en los inicios de la economía global: de las minas a la moneda, México, El Colegio de México, 2014.

Hopkins, A. G. (ed.), Globalization in World History, Nueva York, Pimlico, 2002.

Humboldt, Alexander von, Ensayo político sobre el Reino de la Nueva España (1808-11), México, Porrúa, 1978.

IBARRA, Antonio, "Mercado colonial, plata y moneda en el siglo XviII novohispano: preguntas para un diálogo amistoso con Ruggiero Romano", en Historia Mexicana, xLIx: 2 (194) (oct.-dic. 1999), pp. 279-308.

Inikori, Joseph E., Africans and the Industrial Revolution in England. A Study in International Trade and Economic Development, Cambridge, Cambridge University Press, 2002.

Iwasaki Cauti, Fernando, Extremo Oriente y Perú en el siglo XVI, Madrid, Mapfre, 1992. 
Kuntz Ficker, Sandra (coord.), Historia económica general de México. De la Colonia a nuestros días, México, El Colegio de México, Secretaría de Economía, 2010.

Lamikiz, Xabier, "Patrones de comercio y flujo de información comercial entre España y América durante el siglo xviII", en Revista de Historia Económica, 25: 2 (2007), pp. 231-260.

Latham, A. J. H. y Heita KawaKatsu (eds.), Japanese Industrialization and the Asian Economy, Londres, Nueva York, Routledge, 1999.

Lydon, James G., “The Massachusetts Fish Trade with Iberia, 1700-1773”, en The New England Quarterly, 54 (1981), pp. 539-582.

Marichal, Carlos, Bankruptcy of Empire. Mexican Silver and the Wars between Spain, Britain and France, 1760-1810, Cambridge, Cambridge University Press, 2007.

Marien y Arróspide, Tomás Antonio, Tratado general de monedas, pesas, medidas y cambios de todas las naciones, reducidas a las que se usan en España, Madrid, D. Benito Cano, 1789.

Marshall, P. J. (ed.), The Oxford History of the British Empire, vol. 2: The Eighteenth Century, Oxford, Oxford University Press, 1998.

Martínez Shaw, Carlos y José María Oliva Melgar (eds.), El sistema atlántico español (siglos XVII-XIX), Madrid, Marcial Pons, 2005.

Marx, Karl, El capital, México, Fondo de Cultura Económica, 1974, t. I.

Mazín, Óscar y José Javier Ruiz Ibáñez (eds.), Las Indias Occidentales. Procesos de incorporación territorial a las monarquias ibéricas (siglos XVI a XVIII), México, El Colegio de México, Red Columnaria, 2012.

McGuire, John, Patrick Bertola y Peter Reeves (eds.), Evolution of the World Economy, Precious Metals and India, Nueva Delhi, Oxford University Press, 2001.

Miño Grijalva, Manuel, El obraje. Fábricas primitivas en el mundo hispanoamericano en los albores del capitalismo (1530-1850), México, El Colegio de México, 2016. 
Mrtchell, B. R., British Historical Statistics, Cambridge, Cambridge University Press, 1988.

Morineau, Michel, Incroyables gazettes et fabuleux métaux. Les retours des trésors américains d'après les gazettes hollandaises, $16^{e}-18^{e}$ siècles, París, Maison des Sciences de l'Homme, 1985.

MuldRew, Craig, "Atlantic World, 1760-1820. Economic Impact”, en CANNY y Morgan (eds.), 2011, pp. 618-633.

Nogues-Marco, Pilar, Tipos de cambio y tipos de interés en Cádiz en el siglo XVIII (1729-1788), Madrid, Banco de España, 2011.

Northrup, David, "Early European Contacts, and the Emergent Diaspora", en Canny y Morgan (eds.), 2011, pp. 38-54.

Oliva Melgar, José María, "La metrópoli sin territorio. ¿Crisis del comercio de Indias en el siglo XviI o pérdida del control del monopolio?”, en MARTíneZ Shaw y Oliva Melgar (eds.), 2005, pp. 19-73.

Osterhammel, Jürgen, La transformación del mundo. Una historia global del siglo XIX, Barcelona, Crítica, 2015.

Pearce, Adrian J., British Trade with Spanish America, 1763-1808, Liverpool, Liverpool University Press, 2007.

Pearson, Michael N., "Asia and World Precious Metal Flows in the Early Modern Period”, en McGuire, Bertola y Reeves (eds.), 2001, pp. 21-57.

Pieper, Renate, "Las repercusiones de los metales preciosos americanos en Europa, siglos XVI y XviII”, en Hausberger e IbarRa (coords.), 2014, pp. 273-297.

Pieper, Renate, "Die Exportstruktur des spanischen Amerikahandels", en Scripta mercaturae 18 (1984), pp. 61-95.

Pomeranz, Kenneth, The Great Divergence. China, Europe, and the Making of the Modern World Economy, Princeton, Princeton University Press, 2000.

Prados de Escosura, Leandro (ed.), Exceptionalism and Industrialization. Britain and its European Rivals, 1688-1815, Cambridge, Cambridge University Press, 2004. 
Price, Jacob M., “The Imperial Economy, 1688-1776”, en Marshall (ed.), 1998, pp. 78-104.

Richards, J. F. (ed.), Precious Metals in the Later Medieval and Early Modern World, Durham, Carolina Academic Press, 1983.

Riello, Giorgio, Cotton. The Fabric that Made the World, Cambridge, Cambridge University Press, 2013.

Romano, Ruggiero, Moneda, seudomonedas y circulación monetaria en las economías de México, México, El Colegio de México, Fondo de Cultura Económica, Fideicomiso Historia de las Américas, 1998.

Sallmann, Jean-Michel, Le grand désenclavement du monde, 1200-1600, París, Payot \& Rivages, 2011.

SÉRIONnE, Jacques Accarias de, Les intérêts des nations de l'Europe, dévélopés relativement au commerce, París, Desain, 1767, vol. 1.

Serrano Mangas, Fernando, Naufragios y rescates en el tráfico indiano durante el siglo XVII, Madrid, Sociedad Estatal Quinto Centenario, 1991.

SOMbart, Werner, "Der Kampf um die Edelmetalle im Zeitalter des Frühkapitalismus, vornehmlich im 16., 17. und 18. Jahrhundert”, en Weltwirtschaftliches Archiv, 11 (1917), pp. 147-170.

TANDeter, Enrique, Coacción y mercado. La minería de la plata en el Potosí colonial, Buenos Aires, Editorial Sudamericana, 1992.

TePaske, John J., “New World Silver, Castile, and the Philippines, 1590-1800”, en RichaRds (ed.), 1983, pp. 425-445.

Tracy, James D. (ed.), The Rise of Merchant Empires. Long Distance Trade in the Early Modern World, 1350-1750, Cambridge, Cambridge University Press, 1990.

Van Cauwenberghe, Eddy (ed.), Precious Metals, Coinage and the Changes of Monetary Structures in Latin-America, Europe and Asia, Lovaina, Leuven University Press, 1989.

Von Glahn, Richard, “Myth and Reality of China’s Seventeenth-Century Crisis”, en Journal of Economic History, 56 (1996), pp. 429-454. 
VRIEs, Peer, State, Economy and the Great Divergence. Great Britain and China, 1680s-1850s, Londres, Nueva York, Bloomsberry Academic, 2015.

Williams, Eric, Capitalism \& Slavery, Chapell Hill, University of North Carolina Press, 1944.

Wills, John, "European Consumption and Asian Production in the Seventeenth and Eighteenth Centuries", en Brewer y Porter (eds.), 1994, pp. 133-147.

Yuste, Carmen, El comercio de la Nueva España con Filipinas, 1590-1785, México, Instituto Nacional de Antropología e Historia, 1984.

Yuste, Carmen, Emporios transpacíficos. Comerciantes mexicanos en Manila, 1710-1815, México, Universidad Nacional Autónoma de México, 2007.

Zeuske, Michael, Sklavenhändler, Negreros und Atlantikkreolen: Eine Weltgeschichte des Sklavenhandels im atlantischen Raum, Berlín, Walter de Gruyter, 2015.

Zhao, Gang, The Qing Opening to the Ocean. Chinese Martime Politicies, 1684-1757, Honolulu, University of Hawai’i Press, 2013. 